\title{
How far can marine species go? Influence of population biology and larval movement on future range limits
}

\author{
Piers K. Dunstan*, Nicholas J. Bax \\ CSIRO Marine and Atmospheric Research, GPO Box 1538, Hobart, Tasmania 7001, Australia
}

\begin{abstract}
The range of a marine species varies with a wide range of factors including temperature, currents, interspecific interactions and available habitat. Invasive species offer insights into the processes that influence range expansion because they are in the initial stages of an expansive period. We modelled the range expansion of an invasive seastar with an extended larval period throughout southern Australia using a linked physical and biological model. We found that the establishment of new populations was dependent on larval supply and, critically, on the ability of new habitats to retain larval production within the local habitat to compensate for Allee effects at low population densities. Larval supply from existing populations determined the locations of invasions, whereas local retention of larvae determined how fast and how large a population could grow. Increased diffusion dispersed larvae to areas otherwise inaccessible to them in a purely advective model, and had the potential to increase establishment probabilities. Range extension progressed as new populations were established downstream of source populations in locations where the retention of locally produced larvae was sufficient to generate long-term positive growth rates.
\end{abstract}

KEY WORDS: Dispersal $\cdot$ Allee $\cdot$ Larval retention $\cdot$ Population dynamics

\section{INTRODUCTION}

The boundaries of species ranges are leaky. At any one time, a species might be expanding or contracting its range following changes in dispersal patterns, habitat, or the stochastic ebb and flow of patchy populations at the species' margin. Understanding how species' ranges expand, contract, or shift is a key element in understanding current biodiversity patterns and how they might alter in response to changing environmental conditions (Holt \& Keitt 2005). Failure to appreciate the flux in species' occupation of space, including source and sink dynamics, can reduce the effectiveness of spatially distributed management (e.g. design of no-take fishery reserves) (Sale et al. 2005).

The dispersal of marine benthic invertebrates is typically determined by the dispersal of the larval phases, which are strongly influenced by the prevailing oceanic current dynamics (Possingham \& Roughgarden 1990, Gaylord \& Gaines 2000, Siegel et al. 2003). Observing that marine species' boundaries are often clustered around areas of opposing ocean currents, Gaylord \& Gaines (2000) suggested that ocean currents rather than commonly assumed environmental limits (especially temperature) may constrain a species' distribution. Simple flow fields - inshore/offshore advection and eddy effects - can lead to 1- or 2-way barriers, with barrier leakiness determined by the species' life-history characteristics and temporal variability in the current fields (Gaylord \& Gaines 2000, Palumbi et al. 2003).

Viewed over longer time periods, species distributions are dynamic, with limits wandering across space (Graham et al. 1996). Thus, the distributions that we observe today are 'snapshots of the slowly shifting wavefronts of sluggishly invasive or contractive species, responding to past climatological events' (Holt et al. 2005). Established species' ranges can be considered the realised extent of a previous invasion process. With little ongoing expansion or contraction, it can be impossible to distinguish between factors such as habitat suitability, present and historic physical bound- 
aries, interspecific competition and environmental gradients that may limit an established species' extent (Holt et al. 2005). As the intensity of climatological events speed up, so will species' response through distributional changes; those species with the greatest capacity to respond being most likely to gain from accelerated climate change (Thomas et al. 2001, Parmesan \& Yohe 2003). One group of species with a proven capacity to adapt to new environments are newly successful invasive species - species that successfully colonise a new environment following their introduction by an infrequent vector (typically anthropogenic) (Sax et al. 2005). Changes in the distributions of newly invasive species are likely to be both rapid and informative of the processes that constrain and promote changes in the distribution of more established species, and may allow prediction of future changes (Kinlan \& Hastings 2005).

Invasions in marine systems will typically move as jumps between locations or nodes (e.g. Thresher et al. 2003) rather than as a constant wave front, and the prevailing current dynamics will be critical in determining the extent of spread and the stability of populations (Possingham \& Roughgarden 1990, Gaylord \& Gaines 2000). In the simplest case of a single invasion following successful transportation from another region, the establishment of a population will be determined by the equilibrium between local re-supply of competent larvae and the mortality of adults. If re-supply is greater than adult mortality, the population will grow (i.e the intrinsic growth rate $r$ will be greater than 0 ).

Larval re-supply can be expressed as a function of larval production, larval mortality in the water column, and dispersal away from the adult population (meaning that the larvae are effectively lost from that population). Larval production of broadcast-spawning species is strongly influenced by adult density during gamete release, potentially producing Allee effects (negative population growth rates) at low densities (e.g. Dennis 1989). Allee effects can limit or eradicate populations (Lewis \& Kareiva 1993, Keitt et al. 2001), or in this instance prevent them establishing. Critical to the success of a new population overcoming an Allee effect is the continual re-supply of competent larvae from other locations that have an excess of larvae (Keitt et al. 2001). A variety of mechanisms may produce Allee effects, but most studies have focused on facultative interactions between individuals that reduce as population density decreases (Courchamp et al. 1999). A class of these interactions will be changes in reproductive success, with putative mates unable to find one another at low densities and consequent effects on fertilisation. For externally fertilised marine species, Allee effects are likely to be particularly severe because the proportional fertilisation success in a 3-dimensional matrix is often non-linearly related to the density of the reproductive adults (Levitan 1995, Morris 2002, Rowe et al. 2004).

The second process that may limit the establishment of new population at particular sites is the dispersal of competent larvae. If the population at a site is completely open and all locally produced larvae are dispersed away from the population, then the growth rate of the population is independent of its own larval production and completely dependent on external sources of larvae. Conversely, if the population is completely closed (i.e. no larvae dispersed away), then the growth rate is completely dependent on local larval production, which may be affected by density-dependent processes including Allee effects. Clearly, most local populations of established species exist between these 2 extremes, depending on their demographics and the habitat.

In this study we explore the interaction between these 2 aspects of larval supply/production and larval dispersal using a mixture of empirical and modelassimilated data. We could not empirically quantify variability in larval mortality, and assumed that it is constant over the lifespan of the larvae. We modelled the population dynamics of the invasive seastar Asterias amurensis throughout its potential range in southern Australia. The model combines oceanic circulation patterns, limited estuarine exchange and a complete population model, including mortality, growth, reproduction, larval recruitment and larval dispersal. The equations used to describe the proportion of larvae fertilised are based on empirical results (Morris 2002) and explicitly define an Allee effect. When local reproductive adult density is below a critical threshold, fertilisation ceases and the population will go locally extinct unless larvae arrive from external sources.

Asterias amurensis was first identified in Australia in 1992 from samples collected from the Derwent Estuary, Tasmania, in 1982 (Turner 1992; see Fig. 1). Allozyme variation indicates the probable origin of the Derwent Estuary population of A. amurensis to be Japan (Ward \& Andrew 1995). Since 1992, larvae from the Derwent population has spread to Port Phillip Bay (discovered in 1996 and confirmed by allozyme variation), Victoria, where it has established a population approaching 100 million individuals (Parry \& Cohen 2001). The most likely source of these larvae was the ballast water of commercial shipping. The seastar has since been found in 2 other small embayments but has been eradicated and has not been detected in any other locations to date. The risk of further expansion of A. amurensis in southern Australia is a cause for concern, particularly since the seastar is a voracious predator and can potentially have a large effect on benthic communities (Grannum et al. 1996, Ross et al. 
2002). Expansion risk is related to dispersal from (currently 2) source populations and the successful establishment of new self-sustaining populations. Expansion risk can be reduced by restricting dispersal or establishment success. Choosing between alternative ways of achieving this is of interest for the sustainable management of southern Australian ecosystems.

\section{METHODS}

The model has 2 components, a physical model that describes the estuarine and oceanic dispersal of larvae, and a biological model that describes the production of larvae. The model was simulated 1000 times over probability distributions on key input parameters (adult mortality, growth, and settlement success) to explore the range of possible dynamics, and the results summarised over 1000 simulations of $100 \mathrm{yr}$. A summary of model parameters is given in Table 1 .

Oceanographic and estuarine models. MECO (Model of Estuaries and Coastal Oceans), a 3-dimensional, non-linear hydrodynamic model, was used to describe circulation patterns of water across southeastern Australia. It was previously used to describe a wide range of coastal and estuarine systems (Condie et al. 1999, Walker 1999, Bruce et al. 2001). For this study we used the same MECO simulation as Bruce et al. (2001). The model is based on cells with an area of

Table 1. Defined model parameters and their sources

\begin{tabular}{|c|c|}
\hline Parameter & Definition \\
\hline \multicolumn{2}{|c|}{ Biological parameter } \\
\hline $1_{\infty}$ & Maximum ray length of seastar arm $(\mathrm{cm})$ \\
\hline$l_{t}, l_{t+1}$ & Ray length at times $t$ and $t+1$ \\
\hline$K$ & von Bertalanffy growth coefficient \\
\hline$N_{t}^{a}$ & Adults of age $a$ at time $t$ \\
\hline$Z$ & Mortality rate from time $t-1$ to time $t$ \\
\hline$\Delta$ & Local density of adults in a cell per $\mathrm{m}^{2}$ \\
\hline$p(\Delta)$ & $\begin{array}{l}\text { Probability density function for the density of } \\
\text { seastars in an estuarine or oceanic cell }\end{array}$ \\
\hline$a, b, c, w$ & $\begin{array}{l}\text { Parameters for pert distribution defining the } \\
\text { minimum, most likely values, and maximum } \\
\text { and the spread of the distribution, respectively }\end{array}$ \\
\hline$E_{a}$ & $\begin{array}{l}\text { Number of eggs produced by a female seastar } \\
\text { of age } a \text {, adjusted for the density of seastars }\end{array}$ \\
\hline$L$ & $\begin{array}{l}\text { Number of larvae produced by a population in } \\
\text { a cell }\end{array}$ \\
\hline$A_{f}^{a}$ & Number of adult female seastars of age $a$ \\
\hline$F_{\Delta}$ & Percent of eggs fertilised at density $\Delta$ \\
\hline$S$ & Settlement probability $=0.5$ \\
\hline$Z_{\mathrm{L}}$ & Larval mortality rate $=0.098$ \\
\hline \multicolumn{2}{|c|}{ Physical parameter } \\
\hline$D$ & Eddy diffusivity constant $\left(\mathrm{m}^{2} \mathrm{~s}^{-1}\right)$ \\
\hline
\end{tabular}

$22000 \times 22000 \mathrm{~m}$, distributed in a $47 \times 136$ cell grid, covering a total area of $1034 \times 2992 \mathrm{~km}$ (Fig. 1). The model was driven by seasonal climatologies of wind, salinity, sea level and temperature. As a consequence, the currents generated from this model represent a typical year and do not vary annually. Finer-scale current patterns than those represented by a $22000 \times$ $22000 \mathrm{~m}$ grid cell are not represented by this model. Currents to a depth of $10 \mathrm{~m}$ were used in the analysis because Asterias amurensis larvae are known to be distributed primarily in the first $10 \mathrm{~m}$ of the water column (Bruce et al. 1995).

Larval densities, rather than individuals, were used in the model because early analyses indicated that population establishment is driven by rare events that would be excluded by tracking a set number of individuals. Larval densities were advected from between adjacent cells using van Leer's scheme (van Leer 1974), a monotonic, upstream-biased differencing scheme, which approximates a Lagrangian scheme and limits numerical diffusion in the model (Allen et al. 1991). We added a centred space-time numerical diffusion scheme (Kowalik \& Murty 1993) to compensate for the diffusive processes not accounted for in the MECO model. Diffusion, originally defined as arising from turbulent eddy motion, is now more loosely used in much of the literature to refer to all the flow structures that occur at time and space scales smaller than those used to model the advective processes, e.g. eddy diffusivity, tides, and random diffusive processes (Largier 2003). Diffusion can also be used to represent interannual variability not represented by seasonal climatologies where the problem of concern covers many years of dispersal (Largier 2003). In this model we used diffusion to represent subgrid scale and interannual variability.

Diffusion is determined by the value of the eddy diffusivity constant $(D)$ in the numerical diffusion scheme.

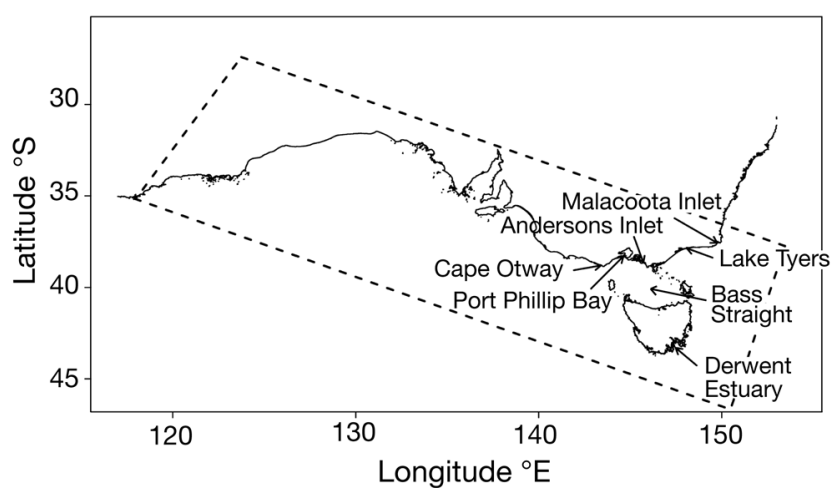

Fig. 1. Spatial extent of the coupled physical and biological model. Bounds of the model are indicated by dashed lines. Locations of particular estuaries and water bodies are noted 
Greater diffusion in the model smears the larvae distribution (or density), increasing the probability that larvae enter estuaries and embayments distant from the main current vectors, and it can potentially move larvae upstream against the prevailing currents (Byers \& Pringle 2006). Values of $D$ can vary from 0 to $1000 \mathrm{~m}^{2} \mathrm{~s}^{-1}$ depending on the location, time of year, and the length and time scales of the model used (Largier 2003). We set the value to $400 \mathrm{~m}^{2} \mathrm{~s}^{-1}$ in this model, but test the robustness of results to values from 0 to $1000 \mathrm{~m}^{2} \mathrm{~s}^{-1}$.

Different embayments, estuaries or lagoons will be more or less likely to support the development of selfsustaining populations of Asterias amurensis. Factors such as available habitat, depth, productivity, and exchange with the ocean would be expected to influence initial establishment probability, development of a self-sustaining population and, ultimately, population size. A total of 97 estuaries on the Tasmanian and southern Australian mainland coastline for which data were available were included in the model. Data on the residence time (the average amount of time that biological particles will spend in the estuary) of these estuaries were obtained from the Simple Estuarine Response Model (SERM II; www.per.marine.csiro.au/ serm2/index.htm). Estuaries are represented either as lagoonal or as a salt-wedge/tidal estuary. Lagoonal estuaries have only 1 estuarine cell, modelled as a homogenous body of water, and typically have long retention times (up to $180 \mathrm{~d}$ ). Salt-wedge/tidal estuaries have 5 cells, and the residence time of each cell increases with distance from the estuary mouth. Information on the surface area of each estuary included in the model was obtained from the OzEstuaries database (Geoscience Australia; www.ozestuaries.org). Water surface area and residence times vary with estuary. Water surface area is used to calculate the density of adult populations.

Larvae retention in the estuaries is a function of the number of cells and the residence time of each cell in the estuary. The residence time of the cell determines the movement of larvae across the face of each cell, with an upwind diffusion scheme in salt-wedge estuaries. Estuarine exchange occurs between the estuary and the oceanic cell adjacent to the estuary position. Daily exchange is calculated as $1 /$ residence time (d) and gives the proportion of estuarine volume exchanged per day, assuming that the volume of water in the estuary will be replaced completely after the residence time. Exchange of water with the oceanic cells (flow in and out of the estuary) is determined by the residence time of the estuarine cell adjacent to the oceanographic cell so that the total volume of water in the estuary does not change from day to day. Larvae can both leave and enter an estuary from the adjacent oceanic cell.
Population biology of Asterias amurensis. Growth and mortality: Adult Asterias amurensis are presently limited to 2 estuaries in southern Australia: the Derwent Estuary in southern Tasmania, and Port Phillip Bay in southern Victoria. It is estimated that there are 4 $\times 10^{6}$ seastars with a ray length of $5.5 \mathrm{~cm}$ or more in the Derwent Estuary (S. D. Ling et al. unpubl. data) and $9 \times$ $10^{7}$ seastars in Port Phillip Bay (Parry \& Cohen 2001). To predict the spread of $A$. amurensis across southern Australia, it is necessary to understand the dynamics of these populations and their reproductive output.

In 2000, CSIRO - with help from community groups - held a seastar clean-up around the docks in the Derwent Estuary. Seastars were collected by divers, and the ray length of each seastar (to the nearest $5 \mathrm{~mm}$ ) was measured for a proportion of those collected. This data set provided the best data with which to assess the growth and mortality of Asterias amurensis in the Derwent Estuary. The size frequency data from the community collection were used to estimate the von Bertalanffy growth coefficient $K$ (Hilborn \& Walters 1992). Values of $K$ for the first year of post settlement growth were estimated from distribution of lengths for seastars from 3 to $8.5 \mathrm{~cm}\left(l_{\infty}=\right.$ maximum ray length $(21 \mathrm{~cm}), l_{t}=$ length at time $t, l_{t+1}=$ length at time $\left.t+1\right)$. This distribution was resampled with replacement 1000 times in order to generate a distribution of sizes in the first mode, and subsequently a distribution of values for $K$. Calculating the distribution of possible $K$ values allowed us to estimate the variability in growth, rather than relying on a single estimate. A pert distribution (parameters $a=$ minimum, $b=$ most likely, $c=$ maximum, and $W=$ weight or spread of the distribution; $a=0.15, b=$ $0.291, C=0.52, w=3.432$ ) was fitted to the bootstrapped $K$ distribution using maximum likelihood estimates for a $\beta$-distribution. A pert distribution is a modified $\beta$-distribution, $\beta$ (shape1, shape 2$)(c-a) a$, where shape1 and shape 2 are transformed to $b$ and $w$, respectively. The minimum and maximum values were specified from the data ( $a$ and $c$ ), and the values of $b$ and weight (mostlikely value and the spread of the distribution) were estimated. This distribution was then used to define the range of growth rates for $A$. amurensis.

The dynamics of established local populations at any particular site were modelled as an age structured, constant mortality model:

$$
N_{t}^{a}=N_{t-1}^{a-1} \mathrm{e}^{-Z}
$$

where $N_{t}^{a}$ is the population of size class $a$ at time $t$, $N_{t-1}^{a-1}$ is the population in the previous time and age class, and $Z$ is the mortality rate from year $t-1$ to year $t$. All calculations for population dynamics, growth, and reproduction are site-specific (i.e. the local population dynamics in 1 oceanic or estuarine cell are independent of all others), even though larval dis- 
persal can occur between cells and sites. We estimated the adult $Z$ using the distribution of $K$-values and the distribution of seastar sizes from the Derwent Estuary. We used a standard fisheries technique to combine the von Bertalanffy growth equation with the age-based model (Eq. 1) and used the right-hand slope of the length-frequency distribution to calculate $Z$ using nonlinear least squares. Calculating $Z$ in this manner is not an optimal solution, but without additional collections or mark-recapture experiments is the best method available. We generated 10000 random values of $K$ from the estimated $K$ distribution and used these to calculate a distribution of $Z$ values. A pert distribution of $Z$ values was fitted using maximum likelihood estimation for values of $b$ and weight, fixing values for $a$ and $c(a=0.3, b=0.57, c=0.98, w=3.315)$. In the model implementation, we used $28 \mathrm{~d}$ (approx. 1 mo) age classes to allow for changes in recruitment from month to month, and adjusted $Z$ by $28 / 364$ to account for the shorter interval between age classes.

To specify the initial conditions of the model, the age distributions of the current populations in 2 locations were needed. Using the most likely value of $Z(0.57)$, we calculated the stable age-length distribution of the 2 existing populations in the Derwent Estuary and Port Phillip Bay. The abundance of Asterias amurensis with a ray length of $>5.5 \mathrm{~cm}$ (approx. $1 \mathrm{yr}$ old and easy to identify) in the Derwent Estuary is estimated at $4 \times 10^{6}$ (S. D. Ling et al. unpubl. data), and in Port Phillip Bay the abundance of seastars greater than $5.5 \mathrm{~cm}$ was $9 \times 10^{7}$ (Parry \& Cohen 2001). Using this information combined with the population model (Eq. 1) and an estimate of $Z$, we were able to calculate the number of seastars of $<5.5 \mathrm{~cm}$ under the assumption that the population was neither declining nor expanding.

Density and fertilisation: Because Asterias amurensis is an externally fertilised broadcast-spawning species, the density of reproductively mature adults is critical in determining the proportion of eggs fertilised. The fundamental reproductive characteristics of $A$. amurensis have been estimated from seastar populations in the Derwent Estuary (Morris 2002). Morris (2002) estimated that an adult female produced an average of 10600 eggs g $^{-1}$ dry gamete. Grannum et al. (1996) estimated the length $(\mathrm{cm})$ to weight $(\mathrm{g})$ relationship, and Morris (2002) the $g$ dry gamete released $\mathrm{g}^{-1}$ seastar wet weight. Combining these 2 relationships with average egg number and the von Bertalanffy growth curve gives:

$$
\begin{gathered}
E_{a}=3059 \times R^{2.6}-274540 \\
R=l_{\infty}-l_{\infty} \mathrm{e}^{-K a}
\end{gathered}
$$

where $R$ is the estimated von Bertalanffy ray length, $K$ is the von Bertalanffy growth coefficient, and $E_{a}$ is the number of eggs for age a. If we solve Eq. (2) for the length of seastars when egg production equals zero (i.e. $E_{a}=0$ ), converting age $a$ to length using the von Bertalanffy equations, we can determine that females do not produce eggs until they have a ray length of greater than $5.52 \mathrm{~cm}$, similar to the estimate given by Byrne et al. (1997). Using the population model (giving the number of females in each age class) and the pert distributions for $K$ (giving the number of eggs per individual for each age class), the total reproductive output of the female portion of the local population can be calculated.

The fertilisation success of starfish among populations of different densities was calculated using a 3dimensional fertilisation model that allowed for diffusion of gametes in 3 dimensions (Morris 2002, p. 52). Fertilisation depends on the close proximity of male and female adults (i.e. within metres). The relationship between local density within a defined location $(\Delta$, seastars $\mathrm{m}^{-2}$ ) and fertilisation (from Morris 2002) was estimated from the model as:

$$
F_{\Delta}=0.165 \times \ln (\Delta)+0.609
$$

where $F_{\Delta}$ is the proportional (range 0 to 1 ) fertilisation success of density $\Delta$. This equation specifies an Allee effect. When $\Delta$ is less than 0.025 seastars $\mathrm{m}^{-2}$, the proportion of eggs fertilised equals zero, and the population must be sustained from external sources.

In the most recent survey of Asterias amurensis in the Derwent Estuary, seastar densities calculated for transects across a range of depths showed a bi-modal distribution with large numbers at low densities $\left(<0.05 \mathrm{~m}^{-2}\right)$ and a second mode at higher densities $\left(\sim 0.12 \mathrm{~m}^{-2}\right)$ (S. D. Ling et al. unpubl. data). From these data, we fitted a mixture of 2 negative binomial distributions (Everitt \& Hand 1981) using the mix package (www.math.mcmaster.ca./peter/mix/mix.html) for R (www.r-project.org). The 2 distributions were added together by proportionally adding the probability density functions $1(p(\Delta))$ to generate a final probability density distribution:

$$
p(\Delta)=p_{1} \psi_{1}\left(\mu_{1}, \operatorname{size}_{1}\right)+p_{2} \psi_{2}\left(\mu_{2}, \operatorname{size}_{2}\right)
$$

The proportions $\left(p_{1}\right.$ and $p_{2}$ ) and the parameters for each negative binomial distribution $\psi$ (mean density $\mu$, and 'size', the measure of dispersion) can be estimated from the data. The 2 negative binomial distributions were fitted to the current distribution of densities in the Derwent Estuary, resulting in $p_{1}=0.903, \mu_{1}=12.79$, size 1 $=0.6798$ for the 1 st (left hand) distribution, and $p_{2}=$ $0.097, \mu_{2}=114.55$, size $_{2}=93.97$ for the 2 nd (right hand) curve. To mimic newly established low-density populations at new sites, the distribution at that site was scaled so that at densities below those seen in the Derwent Estuary, the contribution of the second distribution declines linearly to zero. This means that new popula- 
tions at particular sites are unable to form high-density aggregations (i.e. $\sim 0.12 \mathrm{~m}^{-2}$ ), which will reduce the fertilisation success of these populations. New populations have naturally lower abundances, and we assumed that the higher-density aggregations cannot form. At densities above those seen in the Derwent Estuary, $\mu_{1}$ and $\mu_{2}$ (the average densities) are scaled in proportion to the increase in total density, while the 'size' parameter for the distributions (size ${ }_{1}$ and size ${ }_{2}$, which set the spread of the densities) remains constant. This means that although the density of the population increases, the shape of the distribution remains constant.

The capacity of an area to support a population is not unlimited, and abundances cannot increase forever. The upper limits to local supply of larvae to a population were set by the fecundity of the adult populations at that location, limiting the self-replacement rate at higher densities. In many echinoderm species, higher densities lead to lower gonad indices as a consequence of intra-specific competition for limited food resources, reducing the reproductive output per individual (Levi$\tan 1991$, Wahle \& Peckham 1999, Muthiga \& Jaccarini 2005). At a population level, pest densities of Asterias amurensis are capable of removing a significant proportion of the available food from their preferred habitat (Ross et al. 2002), and the gonad indices of seastars removed from food sources drops significantly (S. D. Ling et al. unpubl. data). Based on this evidence, we assumed that the availability of food (a function of local population density) limits the total reproductive output of a population within a site. Other density-dependent processes may act on either the larvae or post-settlement survival, but we had no information on the functional shape or variables of these processes. As the local population size and density increases beyond the current average density of seastars in the Derwent Estuary $\left(0.103 \mathrm{~m}^{-2}\right)$, the reproductive output of female seastars was reduced from 100 towards $0 \%$ as a linear function of the population densities of the past $2 \mathrm{yr}$. This simulates the sequential removal of food sources by seastar populations and the subsequent reduction in egg and sperm production. This process only operates once seastars have exceeded the pest densities seen in Australia. For populations reliant on local supply (e.g. those in the Derwent Estuary and Port Phillip Bay), this ultimately limits the local population. (However, the population may continue to export dispersed larvae to other sites.)

Using the information on the number of female seastars at age $a$ (Eq. 1), the total number of eggs produced by each female of age a (Eq. 2), and the fertilisation rate of eggs at density $\Delta$ (Eq. 3 ), we can calculate the number of fertilised eggs-and consequently larvae-produced at a particular density. Further, because we know the distribution of densities at any particular site (from the mixture of negative binomial distributions), we can calculate the proportion (i.e. $p(\Delta)$, Eq. 4$)$ of adults across the range of densities predicted at that site. The number of larvae produced $(L)$ at a location in a given year will be:

$$
L=\sum_{a=0}^{a=96} \sum_{\Delta=\Delta_{\min }}^{\Delta=\Delta_{\max }} p(\Delta) \times A_{f}^{a} \times E_{a} \times F_{\Delta}
$$

where $A_{f}^{a}$ is the female proportion of the population $(0.5 \times$ total population) of age $a$. The derivation of values for numbers of eggs $\left(E_{a}\right)$ and proportion fertilised $\left(F_{\Delta}\right)$ are given above.

The current patterns used in the oceanographic model vary daily, and change significantly with season. Thus, larval dispersal patterns depend in part on the seasonality of larval release. Larval release in the model occurs between 1 July and 15 October each year, with maximum release occurring on 15 August (S. D. Ling et al. unpubl. data). Given that the maximum observed larval period is $120 \mathrm{~d}$ (Bruce et al. 1995), larvae will be present in the model from July to mid- February the following year, corresponding with predicted larval presence in the Derwent Estuary (Bruce et al. 1995, C. Sutton unpubl. data).

Larval duration: The larval duration of Asterias amurensis varies with temperature (Bruce et al. 1995). At low temperatures $\left(<9^{\circ} \mathrm{C}\right)$ larval duration can exceed $100 \mathrm{~d}$, but as the water temperature increases, the larval duration decreases. Bruce et al. (1995) fitted an exponential curve to experimental data on larval duration and temperature $\left({ }^{\circ} \mathrm{C}\right)$ :

$$
\text { Duration }=\mathrm{e}^{-0.11 \times \text { temperature }+5.58}
$$

Temperatures in the model ranged between 7 and $22^{\circ} \mathrm{C}$, yielding a duration of between 122 and $23 \mathrm{~d}$ before the larvae were competent to settle.

Larval mortality and settlement probability: Estimates of larval survival and settlement success are difficult to obtain. Laboratory studies of Asterias amurensis suggested mortality rates of between 12 and $17 \%$ $\mathrm{wk}^{-1}$ (Sutton \& Bruce 1996). Likewise, settlement success appears to vary between 0 and $100 \%$, depending on the substrate type in laboratory studies (Morris 2002). Neither fine-scale habitat data nor settlement preferences are available, and we assumed that settlement probability is on average the same for each of the oceanic or estuarine cells. Potentially, both larval mortality and settlement could vary with habitat. Larval mortality in the model was estimated using data from the Derwent Estuary and the knowledge that an approximately stable population had been established in the estuary since at least 1982 . With this knowledge and the relationships derived above, we estimated the level of larval mortality that would keep the population 
stable. The consequence of these assumptions is that the average retention time for the Derwent Estuary (15 d) will be the minimum estuarine retention time required to establish a self-sustaining population.

A simplified oceanographic model of the Derwent Estuary linked to the full biological model was constructed to estimate daily larval mortality $\left(Z_{\mathrm{L}}\right)$ and settlement probability $(S)$. In this model, the Derwent Estuary (a salt-wedge estuary with 5 cells) was linked to a single oceanic cell to allow the dispersal of larvae away from the estuary, simulating the loss of larvae through dispersal, and the combinations of $Z_{\mathrm{L}}$ and $S$ that generated a population closest to the existing abundances in the Derwent Estuary were determined. Larval duration was calculated using the water temperatures from the single ocean cell. Several combinations of $Z_{\mathrm{L}}$ and $S$ met this criteria; however, values of $S$ below 0.5 led to unstable oscillations, while values of $S$ greater than 0.8 to 0.9 seemed unreasonably high. Consequently, values of 0.5 for $S$ and 0.098 for $Z_{\mathrm{L}}$ were chosen for all simulations, which is within the range seen in other marine species (Morgan 1995).

Larval dynamics were simulated using an agestructured, constant-hazard model, as for the adult population but with the larvae separated into weekly cohorts. Once the age of the larvae exceeded larval duration (note dependence on temperature), larvae were competent to settle and remained so for $1 \mathrm{wk}$. Larvae could settle if adjacent to the coastline or in an estuary. Larvae settled with a fixed probability $S$ tested against a uniform distribution $(R=0,1)$. Larvae not adjacent to the coastline or in estuaries would die after the competency period of $1 \mathrm{wk}$ was exceeded. We had no information to suggest that deep-water populations are possible in Australian waters, because the only populations seen have been in coastal locations. Values for $S(0.5)$ and $Z_{\mathrm{L}}(0.098)$ are constant across the range of the model.

\section{RESULTS}

\section{Dispersal range}

Larvae are dispersed from the 2 existing populations and spread with time along the coasts of southern Victoria and Tasmania. Port Phillip Bay is responsible for the greatest larval dispersal as a result of its larger adult population and larval production (approx. $10^{12}$ larvae $\mathrm{yr}^{-1}$ ) and the position of the mouth of Port Phillip Bay in Bass Strait. This allows larvae released from Port Phillip Bay to spread across Bass Strait to the Kent and King Island groups and toward the northern coastline of Tasmania (Fig. 2). The Zeehan current (Baines
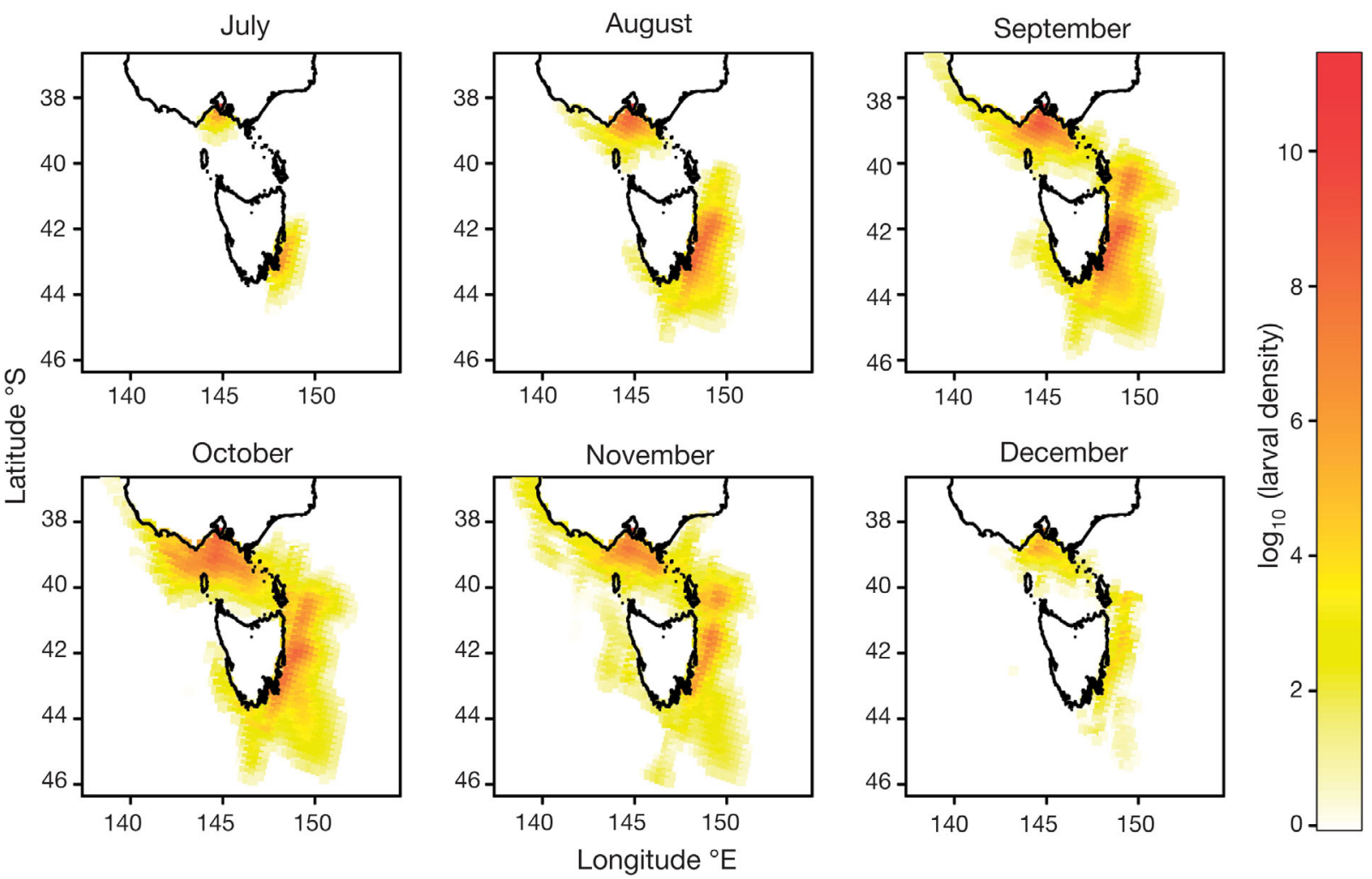

Fig. 2. Asterias amurensis. Larval densities in the Tasman Sea and Bass Strait supplied from established populations in the Derwent Estuary and Port Phillip Bay. Note log scale on colour bar 
et al. 1983) prevents strong westward flow of larvae towards South Australia in winter.

Larval densities are initially highest around the 2 existing populations, with larval numbers reaching $\geq 10^{11}$ larvae within the source estuaries at any one point in time. Total larval output from the Derwent Estuary exceeds $10^{11}$ larvae $\mathrm{yr}^{-1}$, an order of magnitude less than that from Port Phillip Bay $\left(10^{12}\right.$ larvae $\mathrm{yr}^{-1}$ ). Low-density populations (1 seastar $10000 \mathrm{~m}^{-2}$ ) establish all along the Southern Australian and Northern Tasmanian coastlines with very high probability, sourced from populations in Port Phillip Bay (Fig. 3). Although Port Phillip Bay has a very high retention time and consequently very low oceanic exchange, the bay releases a significant number of larvae, which are retained within the Bass Strait region in the prevailing circulation. Populations to the west of Port Phillip Bay establish within 10 model years, but populations to the east of Port Phillip Bay take longer to establish. It is important to note that very few populations established along the east coast of Tasmania, despite the geographic proximity to the Derwent Estuary. Larvae are advected away from the coast at critical moments in the larval phase, resulting in low numbers of recruits to these areas (a conclusion supported by recent plankton surveys in this area, N. J. Bax unpubl. data). High density populations develop in fewer locations and with considerably reduced probability (Fig. 3). The main populations are on the northern coast of Tas-

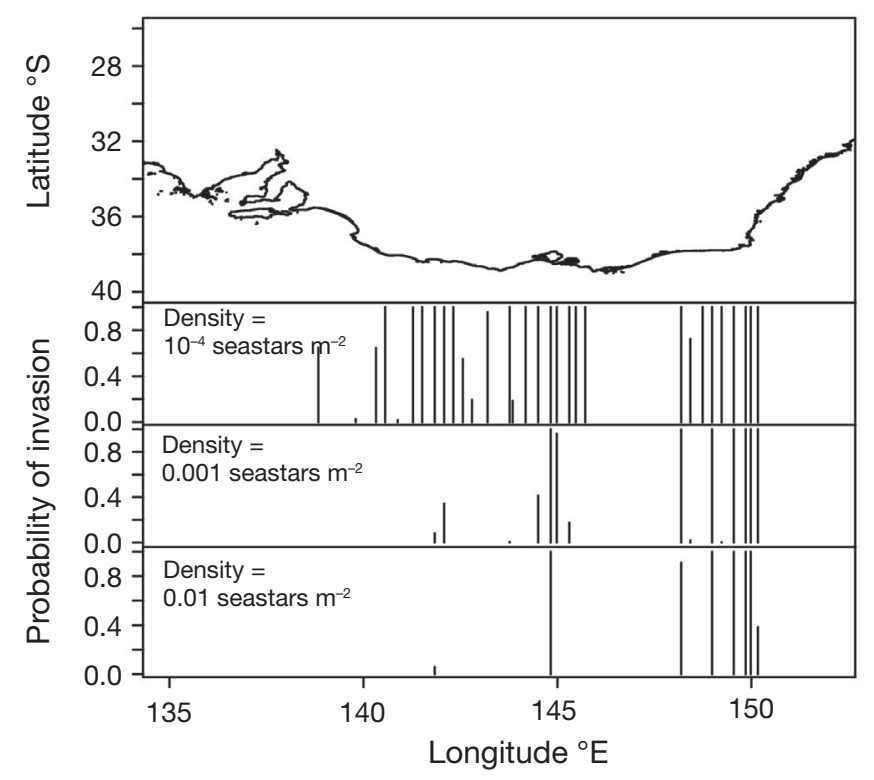

Fig. 3. Asterias amurensis. Probability of populations with densities of $10^{-4}, 0.001$, and 0.01 seastars $\mathrm{m}^{-2}$ occurring along the southern Australian coastline between 135 and $152^{\circ} \mathrm{E}$ longitude. Each location is represented by a separate line, and height of the line indicates the probability of invasion at that density. Probabilities were calculated over 1000 simulations mania and the south-eastern coast of Victoria. The time taken to develop to these numbers is also considerable, generally taking 40 to $50 \mathrm{yr}$ to establish at high densities.

\section{Population growth}

The population dynamics of 4 selected populations Westernport, Andersons Inlet, Lake Tyers, and Mallacoota Inlet-were examined in detail. Both Westernport and Andersons Inlet show rapid establishment of population (Fig. 4a,c); however, the population in Andersons Inlet rapidly reaches a population limit imposed by the low residence time of the estuary. The population growth rate $\left(\ln \left[N_{t+1} \times N_{t}^{-1}\right]\right)$ is a function of local and external larval production and the mortality of the existing adult population. Growth is positive when the influx of larvae exceeds adult mortality. The growth rate of Andersons Inlet rapidly decreases to zero (Fig. 4d) after the initial establishment of the population as a function of both small estuary size and low water retention (average retention time of $5.2 \mathrm{~d}$ ), because larvae produced in the inlet are swept out to sea. The small population is sustained by the input from Port Phillip Bay and the small number retained from the local population.

This contrasts with the situation in the other 3 estuaries examined in detail. Populations in Westernport continue to increase beyond the initial invasion (Fig. 4a), but do so in an approximately linear fashion. This population has a higher growth rate than that in Andersons Inlet (Fig. 4b), reflecting the higher retention time (an average of $50 \mathrm{~d}$ ). The population increases, but the growth rate steadily declines, yielding the linear population increase, and does not reach the limit of the estuary during the $100 \mathrm{yr}$ simulation period.

Lake Tyers is located considerably further eastwards along the Victorian coastline. The estuary has a retention time of approximately $100 \mathrm{~d}$, and consequently more larvae are retained in the estuary than in either Westernport or Andersons Inlet. Growth rates are positive over the duration of the simulation, and remain constant after an initial surge when Asterias amurensis first establishes in the estuary. The population has not reached the limit of the estuary with 100 model years and will continue to grow exponentially until this is reached (Fig. 4e). Mallacoota Inlet is also an estuary with high residence time (92 d) and positive growth once the population establishes (Fig. 4g,h). Despite having a retention time slightly less than that of Lake Tyers, this population grows faster as a result of higher initial inputs of larvae advected from Port Phillip Bay and perhaps the Derwent Estuary and a smaller estuarine area that allows 

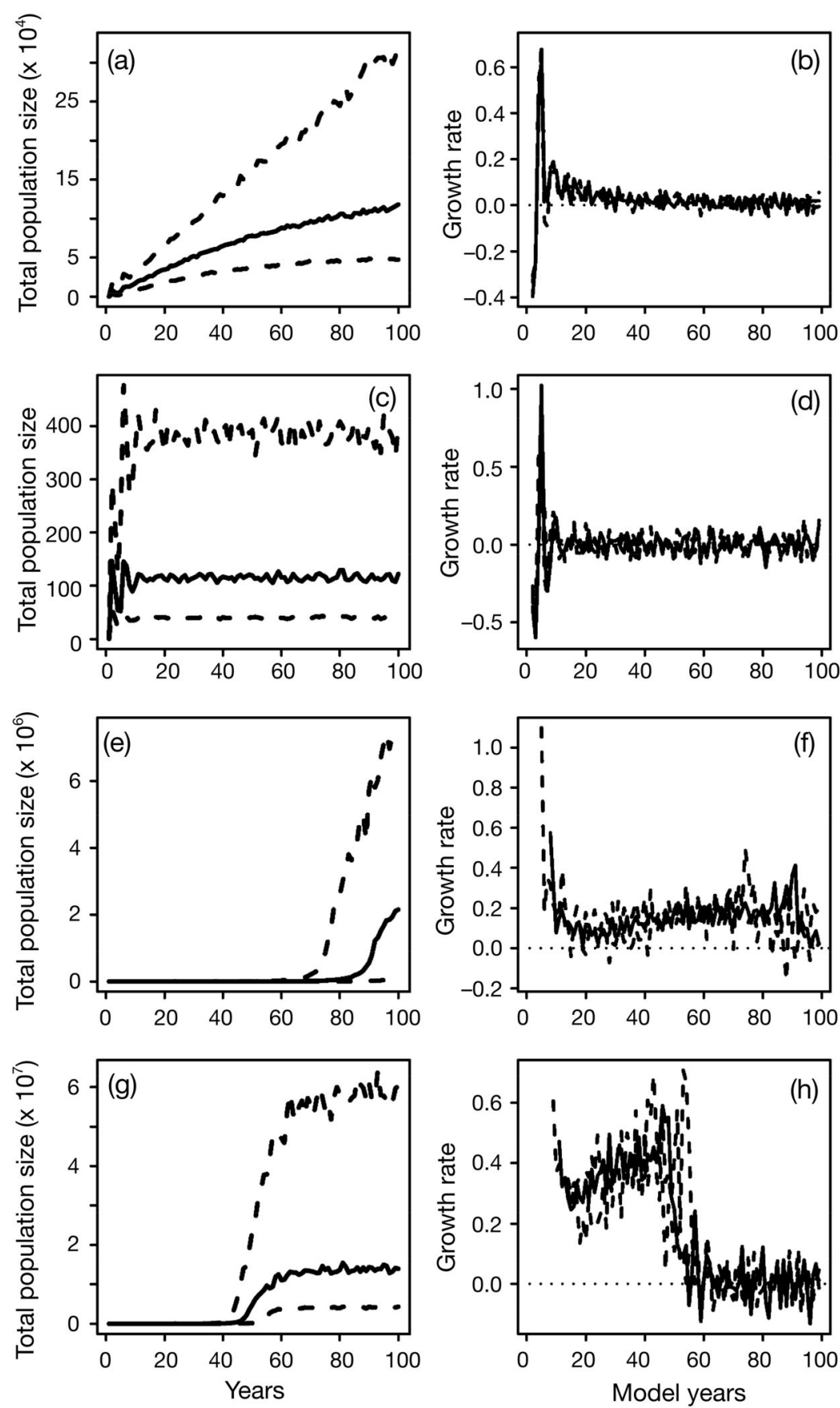

Fig. 4. Asterias amurensis. Population abundances and growth rates at 4 selected estuaries on the southern Victoria coastline. $(\mathrm{a}, \mathrm{b})$ Westernport, $(\mathrm{c}, \mathrm{d})$ Andersons Inlet, $(\mathrm{e}, \mathrm{f})$ Lake Tyers, and $(\mathrm{g}, \mathrm{h})$ Mallcoota Inlet. The solid line is median population size from 1000 simulations and growth rate, and dashed lines the 90th and 10th percentiles. Dotted lines indicate zero growth rate. Note different scales on the $y$-axes. Positions of estuaries shown in Fig. 1

greater aggregation, which increases the fertilisation rate. The population in Mallacoota Inlet begins to reach the population maximum in some simulations after approximately $60 \mathrm{yr}$, at which time the growth rate drops to zero (Fig. $4 \mathrm{~h}$ ).

\section{Growth rate and retention}

The influence of population density and retention time on population growth was explored by estimating the interaction between these mechanisms using linear regressions on the estuaries grouped by residence time. Growth rates and densities were averaged over the 100 yr of each simulation, yielding a total of 1000 combinations of growth and density for each estuary. The data were binned into 3 groups: 0 to 30,30 to 60 , and $>60 \mathrm{~d}$ residence time. Growth rates increased slowest with increasing density in estuaries in the 0 to $30 \mathrm{~d}$ bin (Fig. 5a). However, as residence time increases, the slope of the relationship between density and growth rate also increases, indicating that growth rates in estuaries with longer retention times will increase faster than those with shorter retention (Fig. 5b,c). The lines showing the relationship between density and growth rate in each of the 3 bins of residence time were not parallel (determined using ANCOVA, $F=49.416$, df = $2,7329, \mathrm{p}<2.2 \times 10^{16}$ ), indicating a statistically significant increase in the rate of growth with increasing residence time.

The effects of density-dependent fertilisation success for marine invertebrate broadcast spawners are well established (Levitan 1995), and are simulated in this model as a function of the density of the local populations. The limiting density at which Allee effects occur is constant across all estuaries (i.e. 0 fertilisation when density is $<0.025$ seastars $\mathrm{m}^{-2}$ ). Once the population reaches a certain density, the adults will produce larvae that are released into the water column. However, the fate of those larvae will vary depending on the retention within the local environment. Environments with low retention retain few larvae, and the population growth rate is depressed (Fig. 5a). If retention is sufficiently low (e.g. most of the larvae lost), the population will never retain enough larvae to have a positive growth rate, independent of external sources of larvae. In environments with sufficiently high retention, growth is positive and the rate of growth increases as retention increases (Fig. 5b,c). 

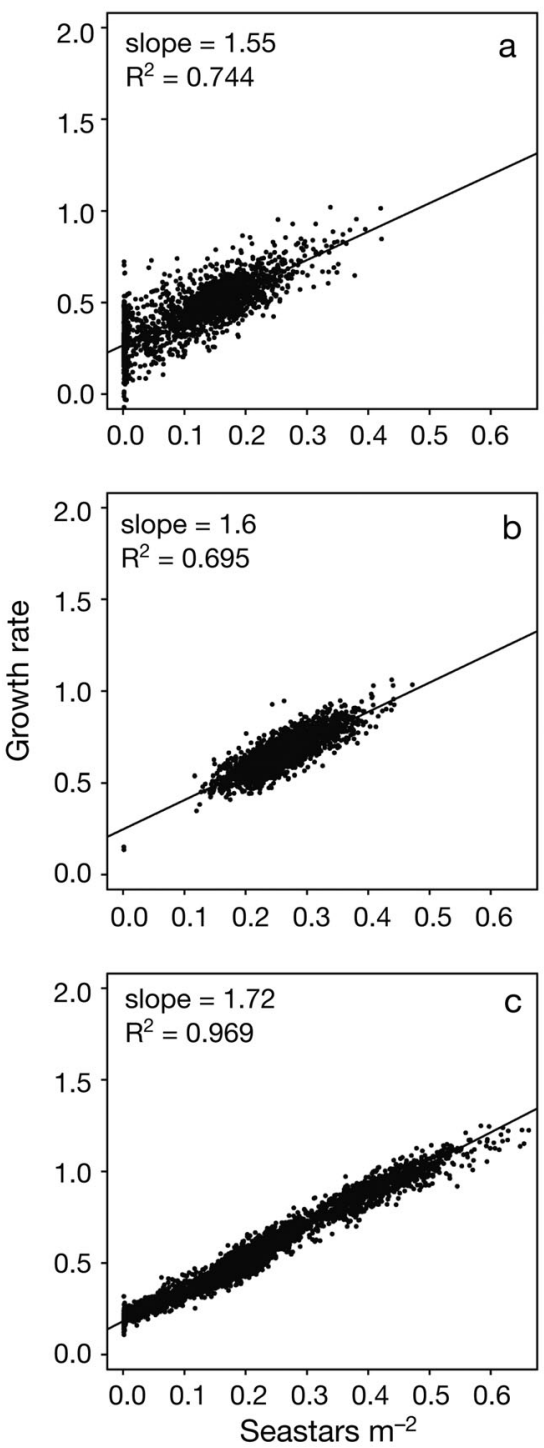

Fig. 5. Asterias amurensis. Growth rates of populations with increasing density for estuaries grouped by residence time. Estuaries are grouped from (a) 0 to $30 \mathrm{~d}$, (b) 30 to $60 \mathrm{~d}$, and (c) $>60 \mathrm{~d}$. Slope of the relationship between density and growth rate is shown

\section{Influence of the diffusion constant on model outcomes}

The dimensionless Peclet number estimates the importance of diffusive relative to advective processes (Largier 2003). Values greater than 1 indicate that the system is advection dominated, and those less than 1 indicate that it is diffusion dominated. The advective currents present during the larval phase of Asterias amurensis vary depending on location and time, but range between $2.3 \times 10^{-7}$ and $0.84 \mathrm{~m} \mathrm{~s}^{-1}$, with a median value of $0.028 \mathrm{~m} \mathrm{~s}^{-1}$. Movement of larvae with the diffusivity constant $D$ set at $400 \mathrm{~m}^{2} \mathrm{~s}^{-1}$ was dominated by

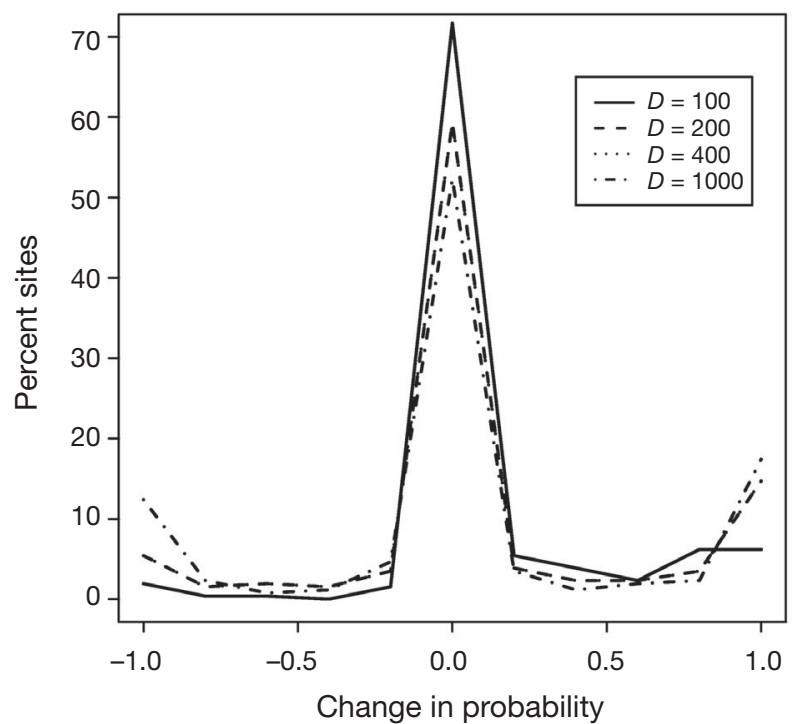

Fig. 6. Asterias amurensis. Influence of increasing eddy diffusivity constant $\left(D_{;} \mathrm{m}^{2} \mathrm{~s}^{-1}\right)$ above 0 on the probability of a site having at least 1 adult at any time during the $100 \mathrm{yr}$ simulation. Each line is calculated as the probability of sites with 1 adult when $D>0$ minus the probability of sites with 1 adult when $D=0$. Values $>0$ indicate increased probability with increasing $D$, and values $<0$ indicate reduced probability. The line for $D=200$ overlaps that for $D=400$

advection (i.e. Peclet number $>1$ ) for $83 \%$ of the currents experienced during the $80 \mathrm{~d}$ larval period.

We explored the influence of changing the value of the diffusivity constant $D$ from 0 to 1000 (Fig. 6). This encompasses the range encountered from coastal to offshore environments (Largier 2003). For most sites, the probability of receiving at least 1 larva during the simulation did not change with increasing $D$. The change in probability is symmetric around 0 , indicating that although the particular sites can change with increasing $D$, the total number does not. However, for some sites, increased diffusion changed the probability of receiving a larva. Increased diffusion reduces the concentration of larvae resulting from advection, but low concentrations of larvae are distributed over a wider area. Sites with a small but positive probability of receiving larvae from advective currents would have reduced probabilities of receiving larvae as larval densities declined; in contrast, sites with zero probability of receiving larvae under advective currents could have an increased probability of receiving larvae as larval distribution expanded if they were on the fringes of the advective distribution. A particular case of concern was the establishment of populations within Andersons Inlet, an estuary that has had a recent incursion. When $D$ is set to zero, this location receives no larvae and does not ever establish a population. However, setting $D$ to above zero allows the movement of larvae into this site. 


\section{DISCUSSION}

Species' distributions change over time on both evolutionary and ecological scales. However, human activity has undoubtedly increased the rates of change over many scales, from global (i.e. climate change, Parmesan \& Yohe 2003) to local (introduction of new species, e.g. Mack et al. 2000). Understanding how distributions change will enable better decisions to be made regarding the management of marine systems.

Invasive species provide an indicator of how change might occur (Sax et al. 2005). They provide an unplanned, ecosystem-scale experiment-'one of the great convulsions of the world's flora and fauna' (Elton 1958). A species that does not spread will not be invasive, but which combinations of spreading species and receiving environments lead to a successful invasion event is not as clear (but see Lonsdale 1999, Ruiz et al. 2000, Kolar \& Lodge 2001). The spread of invasive species gives an indication of how native species may spread and what limits their range. It may also be useful in understanding range contractions of threatened species (Wilson et al. 2004). Opportunities for control and perhaps eradication may be determined by the rate with which an invasive species can establish new reproductive populations in a new region (Kolar \& Lodge 2001).

Insights into the spread of invasive species from modelling have been achieved primarily through theoretical models, principally reaction-diffusion and integro-difference equations and empirical estimates of dispersal kernels with linear rates of spread in 2 dimensions (e.g. Lewis \& Pacala 2000, Hastings et al. 2005; see also Shigesada \& Kawasaki 1997). The rate of spread can be reduced by demographic stochasticity and Allee effects (e.g. Lewis \& Kareiva 1993). Simple diffusion models seem adequate for terrestrial species, but are consistently poor in estimating the diffusion coefficients of marine species (Grosholz 1996). This may be due to marine environments/species violating several of the assumptions in the previously mentioned models, namely homogeneity of environment and random movement of individuals. The dispersal of marine species is typically determined by the dispersal of the larval phases, which are strongly influenced by the prevailing oceanic current dynamics (Possingham \& Roughgarden 1990, Gaylord \& Gaines 2000) and their fluctuations or diffusion (Siegel et al. 2003). However, dispersal is just one part of the process supporting population establishment and maintenance. It is apparent that despite consistent larval supply (Fig. 2), not all locations that receive larvae will establish a population (Fig. 3), and that populations will grow at different rates depending on the environmental conditions of the location (Figs. 4 \& 5). The interaction between species' biology, particularly reproductive dynamics, and environmental conditions will ultimately determine the rate of spread of an invasive species. For an established species, these factors further influence the resilience of species to changing environmental conditions, such as climate warming.

\section{Influence of hydrographic and coastline barriers}

In our model, populations established at low densities within $10 \mathrm{yr}$ along the western region of Bass Strait, around King Island and north-western Tasmania. This is a reflection of the circulation patterns in Bass Strait. High densities, which require the successful establishment of a self-sustaining population, are less likely to develop and take longer. The generation of high densities depends on the stochastic nature of larval supply and the hydrodynamics of specific locations. However, all the populations that established populations at a density of $0.1 \mathrm{~m}^{-2}$ in any simulation always had an established population with a density of $10^{-4} \mathrm{~m}^{-2}$ in every simulation (Fig. 3). Sites that can support high densities always had at least low density populations, irrespective of how long it took to attain higher densities. High estuarine retention times were the common factor among all the sites in which high density populations established.

The importance of estuarine retention was highlighted by changes in the population growth at different sites (Fig. 4). A population in an estuary that retained most of the larvae produced was able to grow at a faster rate than that in an estuary that retained proportionally fewer larvae. Conversely, an estuary with low retention could never establish a large population without significant external input from other locations. In the case of Andersons Inlet, the population could never grow beyond 40 to 50 seastars because the estuary could not retain sufficient larvae for the population to be self sustaining, and was stabilised at this level with input from Port Phillip Bay. Although larvae were not tracked, this was the only possible source of larvae for this region. The opposite is true for Mallacoota Inlet: although the population starts from very low levels, the importance of inputs from Port Phillip Bay decreases with time, and eventually the population becomes self-sustaining, growing to very high densities.

Hypothetical ocean current patterns have been shown to impose boundaries on the distributions of marine species with planktonic larvae, limiting their movement into otherwise habitable areas (Possingham \& Roughgarden 1990, Gaylord \& Gaines 2000), and leading to patchy patterns of distribution in otherwise homogenous environments. Similar patterns (i.e. the 
westward restriction of larval movement) were observed in our models, using abstracted representations of local currents. We note that without the movement of larvae from the Derwent Estuary to Port Phillip Bay in the ballast water of ships, it is unlikely that Port Phillip Bay would ever have been invaded. Larvae from the Derwent Estuary are largely dispersed away from the coast and over the continental shelf, where they cannot find appropriate habitat to settle in. Coastal irregularities retain larvae, allowing populations to flourish (Gaylord \& Gaines 2000). In our model, high density populations only occurred to the east of Port Phillip Bay, where the majority of larvae were swept by the prevailing currents (Fig. 3). Populations to the west of Port Phillip Bay were limited to low densities, despite the presence of appropriate habitat in those areas. Within the area with a high density of larval supply (Fig. 2), high densities only occurred in areas with sufficiently high retention (Figs. 3, 4 \& 5). The ultimate distribution of the species is determined by the patterns of larval dispersal, both retention within the local habitat and dispersal to new habitats.

\section{Expanding species boundaries}

Retention in estuaries affects the establishment of new populations. The combination of Allee effects and larval supply will determine the final extent of the invasive species' range (Holt et al. 2005). Keitt et al. (2001) showed that the connectivity of a new population influenced its ability to overcome any Allee effects. Here we extend the results of Keitt et al. (2001) to a system with a range of open and semi-enclosed environments, and show that it is the interaction of connectivity and retention that influences the ability of a new population to overcome Allee effects. As larvae are dispersed and reach new sites, the local density at the new site is too low to sustain a population from local larval supply, and the local population remains reliant on external larval sources. Provided that local retention of larvae is sufficient, local supply will contribute an increasingly greater proportion of the total larval supply to the site over time, creating a positive and rapidly increasing feedback in population growth (e.g. Fig. 4e,g). Conversely, if local retention is small, then the local population can never exceed the threshold for self supply and will always be dependent on external larval supply (e.g. Fig. 4c)

For Asterias amurensis in southern Australia, the importance of Allee effects will vary among locations, as determined by the retention time of the locations and the density of the population within the estuaries. The physical characteristics of habitat affect growth in fundamental ways, potentially driving growth rates negative at low population densities and generating a habitat-derived Allee effect.

Without any anthropogenic mediated dispersal, the range of the species over the next 50 to 100 yr may be limited to populations in Bass Strait and the Victorian coastline. The presence of suitable locations where retention is high limits the speed of range extension and the final range. The movement of larvae up the east coast of Australia, beyond the area covered by this model, may be limited by the East Australia Current, which flows southward along Australia's east coast; however, expansion is still possible against the prevailing currents (Byers \& Pringle 2006). This is despite the fact that if range was based solely on temperature, then Asterias amurensis would extend its range throughout the entire span of the model and beyond. In this model, the final distribution was driven by the interaction between oceanic transport and local retention.

The dynamics of retention and range expansion will change not only with estuary but also with species. Asterias amurensis is a species with a long larval period, up to $120 \mathrm{~d}$. Most other marine species have shorter larval durations, in the order of hours (e.g ascidians and bryozoans) to weeks (e.g. scleractinian corals, Levin \& Bridges 1995). The larval durations of invasive species in Australia range from $120 \mathrm{~d}$ (A. amurensis) to several hours (Undaria pinnatifida), and the range of suitable habitats is correspondingly broad. $U$. pinnatifida seems capable of forming populations along open coastline, and establishing in any location with sufficient hard substrate. Likewise, the New Zealand screwshell Maoricolpus roseus, which has a planktonic period thought to be of a few days (Gunasakera et al. 2005), extended its range from southern Tasmania (where it arrived in the 1920s) to Botany Bay by $2000(1500 \mathrm{~km})$, but has not been detected in any areas to the west of Wilsons Promontory on the Australian mainland, despite extensive sampling. Similarly to $A$. amurensis, it is found as far out as the outer continental shelf in its native range, but its range extension has been almost opposite that of $A$. amurensis - it has colonised open-shelf habitat but has not been transported to the major shipping hub of Port Phillip Bay.

Range expansion is therefore an interaction of larval life history and local environment, especially retention time in this model. As a species' larval duration decreases, a greater proportion of the released larvae can be retained in a given location, or develop in an adjacent area that will boost future recruitment. More larvae are available to maintain the population, which can expand gradually in open environments subject to limits imposed by local currents and habitat requirements, and are less likely to escape the limits imposed 
by coastlines (Largier 2003), unless like Maoricolpus roseus they are located well offshore. Hydrodynamics features may have a strong impact in limiting the final species range.

The relatively easily documented range expansions of invasive species provide ideal opportunities with which to increase our understanding of the factors affecting the dispersal, range expansion, and range contraction of established species that have reached some temporary equilibrium with prevailing environmental conditions. With changing environmental conditions, this information will assist us in predicting how species' ranges are likely to expand or contract (cf. Parmesan \& Yohe 2003). Species with short larval duration might be expected to show gradual changes in range, while species with long larval durations might show rapid (but saltatory) expansions or contractions as source populations decline to below the level at which they can sustain a string of downstream sink populations.

At the same time, the theory of larval dispersal, developed over the years to explain the distributions of species currently at equilibrium with their environment, provides a context in which to contrast management strategies for preventing the spread of newly arrived invasive species. Consideration of larval duration and local circulation patterns will lead to improved understanding of how a particular species will spread, and the role of anthropogenic vectors in that spread. In the present study, we demonstrated that Asterias amurensis will not spread west of Bass Strait unassisted, indicating the importance of the currently developing National System for the Prevention and Management of Marine Pest Incursions (www.affa. gov.au), which will manage all likely vectors of marine invasive species around Australia. Further, we illustrated the importance of invasion nodes-estuaries and embayments where a proportion of larvae can be retained for $90 \mathrm{~d}$, thus contributing to the next generation. These are the areas that will require effective monitoring and response mechanisms if the spread of A. amurensis around Australia is to be halted.

Acknowledgements. We greatly appreciate permission to use data collected by Scott Ling, Caroline Sutton, Craig Johnson and Alice Morris. Vince Lyne and David Griffin contributed useful comments to the draft manuscript and Mike Herzfeld provided the larval advection scheme used. This research was funded by CSIRO and the Natural Heritage Trust of Australia, an Australian Government initiative. Early results were reported in the Evaluation of National Control Plan management options for the North Pacific Seastar Asterias amurensis. That report is an independent review prepared for the Department of Environment and Water Resources by CSIRO. The views expressed in that report and herein are those of the authors and do not necessarily reflect those of the Australian Government or the Minister for Environment and Water Resources.

\section{LITERATURE CITED}

Allen DJ, Douglass AR, Rood RB, Guthrie PD (1991) Application of a monotonic upstream-biased transport scheme to three-dimensional constituent transport calculations. Mon Weather Rev 119:2456-2464

Baines PG, Edwards RJ, Fandry CB (1983) Observations of a new baroclinic current along the western continental slope of Bass Strait. Aust J Mar Freshw Res 34:155-157

Bruce BD, Sutton CA, Lyne V (1995) Laboratory and field studies of the larval distribution and duration of the introduced seastar Asterias amurensis with updated and improved prediction of the species spread based in a larval dispersal model. Final Report to the Fisheries Research and Development Corporation, CSIRO Division of Fisheries, Hobart

Bruce BD, Condie SA, Sutton CA (2001) Larval distribution of blue grenadier (Macruronus novaezelandiae Hector) in south-eastern Australia: further evidence for a second spawning area. Mar Freshw Res 52:603-610

Byers JE, Pringle JM (2006) Going against the flow: retention, range limits and invasions in advective environments. Mar Ecol Prog Ser 313:27-41

Byrne M, Morrice MG, Wolf B (1997) Introduction of the northern Pacific asteroid Asterias amurensis to Tasmania: reproduction and current distribution. Mar Biol 127: 673-685

Condie SA, Longeragan NR, Die DJ (1999) Modelling the recruitment of tiger prawns (Penaeus escelentus and $P$. semisulcatus) to nursery grounds in the Gulf of Carpentaria, northern Australia. Mar Ecol Prog Ser 178:55-68

Courchamp F, Clutton-Brock T, Grenfell B (1999) Inverse density dependence and the Allee effect. Trends Ecol Evol 14:405-410

Dennis B (1989) Allee effects: population growth, critical density, and the chance of extinction. Nat Res Model 3: 481-537

Elton CS (1958) The ecology on invasions by animals and plants. Methuen \& Co, London

Everitt BS, Hand BJ (1981) Finite mixture distributions. Chapman \& Hall, London

Gaylord B, Gaines SD (2000) Temperature or transport? Range limits in marine species mediated solely by flow. Am Nat 155:770-789

Graham RW, Lundelius EL, Graham MA, Schroeder EK and 16 others (1996) Spatial response of mammals to late quaternary environmental fluctuations. Science 272: 1601-1606

Grannum RK, Murfet NB, Ritz DA, Turner E (1996) The distribution and impact of the exotic seastar, Asteria amurensis (Lutken) in Tasmania. In: The introduced northern pacific seastar Asterias amurensis (Lutken), in Tasmania. Australian Natural Conservation Agency, Canberra, p 53-138

Grosholz ED (1996) Contrasting rates of spread for introduced species in terrestrial and marine systems. Ecology 77: 1680-1686

Gunasekera RM, Patil J, McEnnulty FR, Bax NJ (2005) Specific amplification of mt-COI gene of the invasive gastropod, Maoricolpus roseus in planktonic samples reveals a free-living larval life history stage. Mar Freshw Ecol 56: 901-912

Hastings A, Cuddington $\mathrm{K}$, Davies KF, Dugaw CJ and 10 others (2005) The spatial spread of invasions: new development in theory and evidence. Ecol Lett 8:91-101

Hilborn R, Walters CJ (1992) Quantitative fisheries stock assessment. Choice, dynamics and uncertainty. Chapman \& Hall, New York 
Holt RD, Keitt TH (2005) Species' borders: a unifying theme in ecology. Oikos 108:3-6

Holt RD, Keitt TH, Lewis MA, Maurer BA, Taper ML (2005) Theoretical models of species' borders: single species approaches. Oikos 108:18-27

Keitt TH, Lewis MA, Holt RD (2001) Allee effects, invasion pinning, and species' borders. Am Nat 157:203-216

Kinlan BP, Hastings A (2005) What exotic species tell us about rates of population spread and geographic range expansion. In: Sax DE, Gaines SD, Staichowicz JJ (eds) Species invasions: insights to ecology, evolution and biogeography. Sinauer Associates, Sunderland, MA, p 381-420

Kolar CS, Lodge DM (2001) Progress in invasion biology: predicting invaders. Trends Ecol Evol 16:199-204

Kowalik Z, Murty TS (1993) Numerical modeling of ocean dynamics. World Scientific, Singapore, p 61-63

Largier JH (2003) Considerations in estimating larval dispersal distances from oceanographic data. Ecol Appl 13: S71-S89

Levin LA, Bridges TS (1995) Pattern and diversity in reproduction and development. In: McEdward L (ed) Ecology of marine invertebrate larvae. CRC Press, Boca Raton, FL, p 1-48

Levitan DR (1991) The influence of body size and population density on the fertilization success and reproductive output in a free-spawning invertebrate. Biol Bull (Woods Hole) 181:261-268

Levitan DR (1995) The ecology of fertilization in free-spawning invertebrates. In: McEdward L (ed) The ecology of marine invertebrate larvae. CRC Press, Boca Raton, FL, p 123-156

Lewis MA, Kareiva P (1993) Allee dynamics and the spread of invading organisms. Theor Popul Biol 43:141-158

Lewis MA, Pacala S (2000) Modelling and analysis of stochastic invasion processes. Math Biol 41:387-429

Lonsdale WM (1999) Global patterns of plant invasions and the concept of invasibility. Ecology 80:1522-1536

Mack RN, Simberloff D, Lonsdale M, Evans H, Clout M, Bazzaz FA (2000) Biotic invasions: causes, epidemiology, global consequences and control. Ecol Appl 10:689-710

Morgan SG (1995) Life and death in the plankton: larval mortality and adaption. In: McEdward L (ed) The ecology of marine invertebrate larvae. CRC Press, Boca Raton, FL, p 279-321

Morris A (2002) Early life history of Asterias amurensis. PhD thesis, University of Tasmania, Hobart

Muthiga NA, Jaccarini V (2005) The effects of seasonality and population density on the reproduction of the Indo-Pacific echinoid Echinometra mathaei in Kenyan coral reef lagoons. Mar Biol 146:445-453

Palumbi SR, Gaines SD, Leslie H, Warner RR (2003) New wave: high-tech tools to help marine reserve research. Front Ecol Environ 1:73-79

Parmesan C, Yohe G (2003) A globally coherent fingerprint of climate change impacts across natural systems. Nature 421:37-42

Parry GD, Cohen BF (2001) The distribution, abundance and population dynamics of the exotic seastar Asterias amurensis during the first three years of its invasion of Port Phillip Bay (incorporating a report on the Bay Pest

Editorial responsibility: Don Levitan (Contributing Editor), Tallahassee, Florida, USA
Day, 2 April 2000). Report No. 33, Marine and Freshwater Resources Institute, Queenscliff

Possingham HP, Roughgarden J (1990) Spatial population dynamics of a marine ogranism with a complex life cycle. Ecology 71:973-985

Ross DJ, Johnson CR, Hewitt CL (2002) Impact of introduced seastars Asterias amurensis on survivorship of juvenile commercial bivales Fulvia tenuicostata. Mar Ecol Prog Ser 241:99-112

Rowe S, Hutchings JA, Dekkevold D, Rakitin A (2004) Depensation, probability of fertilisation, and the mating system of Atlantic cod (Gadus morhua L.). ICES J Mar Sci 61: $1144-1150$

Ruiz GM, Fofonoff PW, Carlton JT, Wonham MJ, Hines AH (2000) Invasion of coastal marine communities in North America: apparent patterns, processes, and biases. Annu Rev Ecol Syst 31:481-531

Sale PF, Cowen RK, Danilowicz BS, Jones GP and 7 others (2005) Critical science gaps impede use of no-take fishery reserves. Trends Ecol Evol 20:74-80

Sax DE, Gaines SD, Staichowicz JJ (2005) Species invasions: insights to ecology, evolution and biogeography. Sinauer Associates, Sunderland, MA

Shigesada N, Kawasaki K (1997) Biological invasions: theory and practice. Oxford University Press, Oxford

Siegel DA, Kinlan BP, Gaylord B, Gaines SD (2003) Lagrangian descriptions of marine larval dispersion. Mar Ecol Prog Ser 260:83-96

Sutton CA, Bruce BD (1996) Temperature and salinity tolerances of the larvae of the Northern Pacific seastar Asterias amurensis. Centre for Research on Introduced Marine Pests, Technical Report No. 6, CSIRO Division of Fisheries, Hobart

Thomas CD, Bodsworth EJ, Wilson RJ, Simmons AD, Davies ZG, Musche M, Conradt L (2001) Ecological and evolutionary processes at expanding range margins. Nature 411: $577-581$

Thresher R, Proctor C, Ruiz G, Gurney R, MacKinnon C, Walton W, Rodriguez L, Bax N (2003) Invasion dynamics of the European shore crab, Carcinus maenas, in Australia. Mar Biol 142:867-876

Turner E (1992) A northern Pacific seastar, Asterias amurensis, in Tasmania. Aust Mar Sci Assoc Bull 120:18-19

van Leer B (1974) Towards the ultimate conservative difference scheme. II: Monotonicity and conservation combined in a second order scheme. J Comput Phys 14:361-370

Wahle RA, Peckham SH (1999) Density related reproductive trade-offs in the green sea urchin Strongylocentrotus droebachiensis. Mar Biol 134:127-137

Walker SJ (1999) Coupled hydrodynamics and transport models of Port Phillip Bay, a semi enclosed bay in southeastern Australia. Mar Freshw Res 50:469-481

Ward RD, Andrew J (1995) Population genetics of the northern Pacific seastar Asterias amurensis (Echinodermata: Asteriidae): allozyme differentiation among Japanese, Russian, and recently introduced Tasmania populations. Mar Biol 124:99-109

Wilson RJ, Thomas CD, Fox R, Roy DB, Kumin WE (2004) Spatial patterns in species distributions reveal biodiversity change. Nature 432:393-396

Submitted: August 17, 2006; Accepted: March 2, 2007 Proofs received from author(s): August 13, 2007 